\title{
La Orden de Santiago en época Trastámara: UN REPASO HISTORIOGRÁFICO (1971-2017)
}

\author{
Milagros Plaza Pedroche ${ }^{1}$ \\ Universidad de Castilla-La Mancha
}

\begin{abstract}
Resumen
En el presente artículo se concede atención al desarrollo de la producción historiográfica referente a la Orden de Santiago en el ámbito castellanoleonés y en el periodo comprendido entre 1350 y 1500. En él se realiza un balance que permite conocer los vacíos informativos que todavía perviven dentro de este campo y las líneas de investigación que de cara al futuro se abren a los medievalistas.
\end{abstract}

\section{Palabras clave}

Orden de Santiago; Castilla; Historiografía; Líneas de investigación; Vacíos informativos.

\begin{abstract}
The present study focuses on the development of the historiographical production on the Military Order of Santiago in the kingdom of Castile between 1350 and 1500. An evaluation of the information gaps that still remain in this investigation field has been made, in order to make known possible future research lines for medievalists.
\end{abstract}

\section{Keywords}

The Military Order of Santiago; Kingdom of Castile; Historiography; Research lines; Information gaps.

\section{Résumé}

Cet article étudie le développement de la production historiographique sur 1'Ordre de Santiago dans la couronne castillan-léonaise pendant la période comprise entre 1350 et 1500 . Le bilan qu'on y dresse permet de reconnaître les lacunes d'informations qui existent encore aujourd'hui dans ce domaine ainsi que les futures lignes de recherche qui s'ouvrent aux médiévistes.

\section{Mots-clés}

L'Ordre Militaire de Santiago; Le Royaume de Castille; L'historiographie; Les lacunes d'informations.

\section{Introducción}

Las órdenes militares constituyen un tema de estudio clásico que viene despertando un gran interés entre los historiadores desde hace varias décadas, al constituir un instrumento muy representativo del Medievo y un medio privilegiado para acercarse a la realidad de nuestro pasado. Y es que no cabe duda de que estas conforman una línea

1 Personal Investigador en Formación. Correo electrónico: Milagros. PPedroche@uclm.es. 
de investigación de enorme potencial, ya que integran aspectos militares, políticos, económicos, sociales y religiosos; en ellas convergen el relato fáctico y el análisis de las estructuras históricas.

Como no podía ser de otra manera, el seguimiento del que disfrutan ha dotado de un gran impulso su estudio y la publicación de un número nada despreciable de obras vinculadas con la temática; de modo que la investigación sobre estos grupos ha progresado sólida y sistemáticamente. De hecho, los especialistas no solo continúan trabajando campos vinculados al terreno de las milicias, sino que, desde hace ya algunos años, se vienen preocupando también por conocer el panorama historiográfico existente en torno a ellas. Esto ha propiciado la reiterada aparición de repertorios comentados de excelente calidad, como el Derek W. Lomax, que fue el primero en ver la luz en 1976 (68), el de Philippe Josserand en 1998 (56) y el de Ladero Quesada dos años más tarde (66). Igualmente resulta obligado mencionar las esclarecedoras páginas que el profesor Francisco Ruiz ha dedicado a estas cuestiones en su monografía sobre los orígenes de estos organismos y la repoblación de La Mancha (118) y el trabajo de José Vidente Matellanes Merchán sobre el concreto desarrollo bibliográfico de Santiago entre los años 1974 y 1989 (80). No obstante, si alguien se ha dedicado con verdadero interés a recoger los avances historiográficos alcanzados en relación a la temática, ese ha sido Carlos de Ayala; quien junto a sus colaboradores ha publicado un total de cuatro artículos para los reinos medievales de Castilla y León y la Corona de Aragón y en los que se da cabida tanto a las órdenes militares peninsulares, como a las internacionales $(\mathbf{2 6}, \mathbf{3 0 , 3 3 )}$. El presente trabajo se mueve en la línea de estas últimas publicaciones, es decir, está destinado a analizar cuestiones historiográficas y metodológicas. Sin embargo, con él no se pretende hacer un repaso exhaustivo de las aportaciones realizadas sobre la totalidad de las milicias hispánicas; sino que exclusivamente se presta atención al desarrollo de la producción bibliográfica referente a la Orden de Santiago en el ámbito castellanoleonés y en el periodo comprendido entre 1350 y 1500 . Nuestra intención es reflexionar sobre ella y ofrecer un balance lo más completo posible que permita conocer los vacíos informativos que aún se mantienen dentro de este campo y las líneas de investigación que de cara al futuro se abren a los jóvenes medievalistas.

\section{EI desarrollo de la historiografía sobre la Orden de Santiago a fines del Medievo (1350-1500)}

Los especialistas suelen situar el punto de partida dentro del estudio de estas instituciones en los años sesenta del siglo XX; ya que es en este momento cuando empiezan a publicarse monografías basadas en fuentes documentales inéditas y con nuevos enfoques, de la mano de autores como E. Benito Ruano, J. O'Callaghan y D.W. Lomax ${ }^{2}$. Para Ladero Quesada estas son obras de muy distinto calado, pero que evidencian la

2 Eloy Benito Ruano: "Las Órdenes Militares españolas y la idea de Cruzada", Hispania, 16 (1956), pp. 3-15; Derek W. Lomax: La Orden de Santiago (1170-1275). Consejo Superior de Investigaciones Científicas, 
consolidación de una nueva tendencia que consiste en dotar de mayor protagonismo a las fuentes, frente a ciertas corrientes anteriores de carácter más literario y apologético ${ }^{3}$. Nos encontramos, por lo tanto, ante una modernización de los métodos de estudio, que ha afectado especialmente al periodo comprendido entre 1350 y 1500 . De esta manera se han conseguido cubrir algunos vacíos informativos existentes en torno al último tercio del siglo XIII y todo el XIV, periodos sustancialmente menos estudiados dentro de la evolución medieval de las milicias.

Para el profesor Carlos de Ayala, en las últimas dos décadas, la historiografía dedicada a las órdenes militares ha alcanzado el suficiente grado de madurez como para poder ser considerada como una especialidad dotada de personalidad propia dentro del ámbito del medievalismo. Encuentra pruebas de ello en el hecho de que en diferentes universidades haya equipos de investigadores especializados en la temática, tales como la Universidad Autónoma de Madrid y la Universidad de Castilla-La Mancha; así como en la aparición de revistas científicas centradas en la materia ${ }^{4}$.

Otro indicio de madurez sería la creciente celebración de congresos y encuentros científicos. Aquí debemos recalcar que ha sido en tierras castellano-manchegas donde se ha llevado a cabo la celebración de los congresos científicos de ámbito peninsular más importantes dedicados a estos organismos ${ }^{5}$. Bajo los títulos Las Órdenes Militares en la Península Ibérica y Las Órdenes Militares y la construcción de la sociedad occidental, las reuniones se celebraron en Ciudad Real en 1996 y 2015 respectivamente, gracias al esfuerzo realizado por el Departamento de Historia de la Universidad de Castilla-La Mancha ${ }^{6}$.

No obstante, pese al enorme interés que para la historiografía tiene el tema que nos ocupa, no han sido muchos los autores que de un tiempo a esta parte se han dedicado a estudiar la evolución completa de la milicia santiaguista durante el periodo medieval; y en especial en lo que a la Baja Edad Media se refiere. Como ya hemos indicado con anterioridad, la atención que los especialistas han concedido a su evolución es claramente desigual, ya que la mayor parte de las investigaciones llevadas a cabo

Madrid, 1965; Joseph O'CALlaghan: "The affiliation of the Order of Calatrava with the Order of Citeaux", Analecta Sacri Ordinis Cisterciensis, 15 (1959), pp. 161-193; 16 (1960), pp. 3-59 y 255-292.

3 Miguel Ángel Ladero Quesada: "La investigación sobre Órdenes Militares en la Edad Media hispánica durante los últimos decenios: Corona de Castilla y León”, Las Órdenes Militares en la Edad Media. Volumen I, Ricardo Izquierdo Benito y Francisco Ruiz Gómez (coord.), Universidad de Castilla-La Mancha, Cuenca, 2000, pp. 10-11.

4 Hablamos concretamente de la Militarium Ordinum Analecta, nacida en Portugal a la altura de 1997 y de la Revista de las Órdenes Militares, editada en 2001 por el Real Consejo de las Órdenes Militares.

5 Carlos de Ayala Martínez y Carlos Barquero GoÑi: "Historiografía hispánica y Órdenes Militares en la Edad Media, 1993-2003", Medievalismo: Boletín de la Sociedad Española de Estudios Medievales, 12 (2003), pp. 102-104.

6 Estos congresos vinieron acompañados de dos publicaciones: Ricardo IzQUIERDo Benito y Francisco Ruiz Gómez (coord.): Las Órdenes Militares en la Edad Media. Volumen I y Las Órdenes Militares en la Edad Moderna. volumen II. Universidad de Castilla-La Mancha, Cuenca, 2000. Raquel Torres JimÉneZ y Francisco Ruzz Gómez (coord.): Órdenes militares y construcción de la sociedad occidental. Cultura, religiosidad y desarrollo social de los espacios de frontera (siglos XII-XV). Sílex, Madrid, 2016. 
en las dos últimas décadas se han orientado hacia sus primeros siglos de existencia, quedando las centurias bajomedievales relegadas a un segundo plano dentro de la historiografía.

Las excepciones a esta constante las constituyen las tesis doctorales aparecidas en la década de los ochenta de la mano de Pedro A. Porras Arboledas para la Provincia de Castilla (100) y de Daniel Rodríguez Blanco (106), Miguel Rodríguez Llopis (111) y Rafael Peinado Santaella (92) para las zonas de Extremadura, Murcia y Andalucía, respectivamente. Unas investigaciones que se llevaron a cabo con la intención de alcanzar una visión general de la presencia de esta entidad en sus señoríos del centro y sur peninsular y gracias a las cuales se ha allanado el camino para que puedan elaborarse comparaciones no solo con otras regiones peninsulares, sino también con otras milicias, como la de Calatrava, con la que guarda muchas similitudes en esta etapa final de su desarrollo medieval.

\subsection{Distribución geográfica: el gobierno y la administración de los señoríos santiaguistas}

Actualmente, los estudios que versan sobre la organización de los espacios santiaguistas y al gobierno y la administración de sus señoríos constituyen un elevado porcentaje de la bibliografía relacionada con la institución y cubren casi por completo el espacio del antiguo reino de Castilla. No podemos negar, sin embargo, que dichas investigaciones son algo parcas en lo que al norte peninsular se refiere, puesto que solo José Luis Novo Cazón se ha internado en el conocimiento de la presencia de la orden en este territorio y, más concretamente, en el noroeste gallego (87).

Si bien es cierto que los conocimientos de que disponemos para la parte más septentrional de la Península Ibérica son insuficientes, la situación cambia cuando centramos nuestra atención en la meseta. De hecho, han sido varios los medievalistas que han investigado este espacio en las dos últimas centurias del periodo medieval, como ocurre con Mur i Raudel, que se ha ocupado de la encomienda de San Marcos (86); Segura Graíño, que lo ha hecho de aquellas emplazadas en la Ribera del Tajo (121); y García Luján, que ha elaborado una interesante obra sobre Ocaña entre los siglos XII y XVI (53). Igualmente han sido objeto de atención las zonas de La Mancha y Campo de Criptana gracias a la labor emprendida, de un lado por Porras Arboledas (101) y Martín de Nicolás Cabo (78); y de otro por Buitrago Oliver y sus colaboradores (36). Finalmente, en relación al área extremeña es preciso hacer mención de una novedosa investigación llevada a término por Ángel Bernal Estévez, que ha dado como fruto la publicación de una utilísima obra acerca de la evolución histórica de la encomienda de Mérida (35).

El sureste peninsular es también otra de las zonas que más ha interesado a los medievalistas de un tiempo a esta parte. Aquí se enmarcarían, entre otros, el completo trabajo de Peinado Santaella dedicado a la encomienda de Sócovos (95), los artículos de López Rojo y Sánchez Gil sobre las encomiendas de Santiago en Murcia $(\mathbf{7 2}, \mathbf{1 1 9}$ ) y la aportación que Pretel Marín y Rodríguez Llopis han hecho al estudio de Villanueva 
de la Fuente (103). A este último profesional debemos además otras publicaciones de gran calidad e igual naturaleza, como una completa monografía que atiende a Yeste y Taibilla entre los siglos XIII y XV (110), un artículo sobre los señoríos de la orden insertos en los límites del Reino de Murcia (112) y una contribución orientada hacia los levantamientos campesinos que estallaron en Yeste durante el reinado de Isabel I (113). También es abundante el volumen bibliográfico compuesto en torno al último espacio de los que vamos a ocuparnos: Andalucía. Dentro de esta línea, han sido numerosas las aportaciones que se han realizado al conocimiento concreto de la presencia santiaguista, como las de Peinado Santaella acerca del ámbito granadino y sevillano (89, 90)), la fronteriza Estepa (91) y la encomienda de las Casas de Córdoba (96). Y es que ha sido este especialista quien mayor atención a prestado a la temática; aunque no el único, ya que también Lasarte Cordero nos ha proporcionado un libro que versa sobre el territorio de Estepa (67).

La vida económica y el fisco en tierra de órdenes militares es otro de los puntos en los que debemos detenernos a lo largo de estas líneas, ya que la explotación de sus dominios patrimoniales y jurisdiccionales les generaban cuantiosos y variados beneficios procedentes de las rentas. En la actualidad, la bibliografía de que disponemos para aproximarnos a estas cuestiones en lo que afecta a Santiago es menos numerosa que en los casos anteriores. De hecho, solo hemos encontrado dos investigaciones que sigan esta línea en tierras andaluzas: la de Peinado Santaella, que analiza la estructura de las rentas obtenidas por la entidad en la Andalucía oriental (93); y la de Ladero Quesada, que versa sobre los recursos económicos a los que tenía acceso en esta zona (64). De similar naturaleza son los artículos que Joaquín Pérez Fernández-Figares (98) y María de los Llanos Martínez Carrillo (79) presentaron sobre el arancel de los portazgos que percibía en Castilla y sobre sus rentas y censos en la ciudad de Murcia, respectivamente. También han sido varios los estudios que han abordado la materia de una manera más general; nos referimos al artículo de Peinado Santaella (97), al de Ladero Quesada (63) y al de Porras Arboledas (99).

\subsection{Organización institucional y distribución del poder}

Tras habernos detenido en el gobierno y la administración de los señoríos de la Orden de Santiago, es el momento de abordar la cuestión de su funcionamiento institucional y la distribución del poder dentro de ella en las dos últimas centurias medievales; ya que estos organismos conocieron una acentuada jerarquización en su interior, reflejo del reparto del poder político, económico y eclesiástico. En este sentido observamos que, pese al enorme interés que para la historiografía tiene el tema que nos ocupa, han sido muy pocos los autores que han estudiado de manera conjunta estos aspectos en lo concerniente a nuestra protagonista. De hecho, solo Matellanes Merchán ha editado un trabajo de esta naturaleza, en un intento por delimitar los procesos de jerarquización y vinculación interna en el seno de la institución del siglo XII al XIV (81). 
No obstante, si bien es cierto que las obras generales que giran en torno a la temática son muy escasas, la situación cambia radicalmente cuando dirigimos nuestra mirada hacia el maestre y sus correspondientes soportes económico-institucionales, los maestrazgos; debido a que han sido muchos los interesados en ampliar sus conocimientos sobre esta figura y sus sólidas bases materiales. Así ocurre, por ejemplo, con Carlos de Ayala, que se ha adentrado en estas cuestiones para el ámbito de la Corona de Castilla (28); con Ladero Quesada, que ha hecho lo propio con las mesas maestrales de Calatrava y Santiago (63); y con López Fernández y Carrasco García, que han centrado su atención en Gonzalo Mejía y Lorenzo Suárez de Figueroa, respectivamente $(\mathbf{6 9}, 44)$.

De otro lado, la historia de don Enrique de Aragón la han cubierto prácticamente en su totalidad las recientes publicaciones de Álvarez Palenzuela (21), Rodríguez Blanco (109), Pretel Marín (102) y Madrid Medina (74). Además, en relación a este último maestre disponemos también de un valioso trabajo del ya citado Rodríguez Blanco acerca de los cambios que durante su maestrazgo y, en menor medida, a lo largo del reinado de los Reyes Católicos fueron introduciéndose en la entidad (107). Por el contrario, no existe ninguna publicación hoy en día vinculada exclusivamente a la labor realizada por don Álvaro de Luna y don Juan Pacheco. Pese a ello, han sido varias las que han aparecido para tratar algún aspecto específico de su biografía, como ocurre con las de Calderón Ortega (39, 41), Franco Silva (51), Madrid Medina (75) y Frías Ponce (52).

A diferencia de lo que sucedía en los casos anteriores, el estudio de las restantes dignidades laicas y eclesiásticas que conformaban estos organismos, constituye un porcentaje mínimo de la bibliografía relacionada con la materia, a causa de la escasa popularidad que viene rodeando al tema desde un principio. Por ende, este tipo de investigaciones son alarmantemente escasas; especialmente en lo que afecta a los priores y sacristanes, sobre los que no se ha escrito nada por el momento. Ligeramente mejor es la situación en la que se encuentra el comendador dentro de la producción historiográfica; pues actualmente disponemos de una aportación que se ha internado en el conocimiento de estos delegados del poder maestral en los territorios sobre los que tenían jurisdicción: la de Ángela Madrid Medina (77).

Para finalizar, y antes de cerrar el presente apartado, creemos conveniente subrayar la curiosidad que ha suscitado entre los expertos el papel que la mujer ocupaba en las milicias. A él han dirigido sus esfuerzos Echániz Sans $(\mathbf{4 7}, \mathbf{4 8})$ y Ferrer Vidal (49, 50), quienes han tratado de acercarse a los conventos santiaguistas y en especial al de Sancti Spiritus y al de Santa Eufemia de Cozuelos. De igual forma lo ha hecho Rivera Garretas, al interesarse por la presencia de las mujeres y su posición dentro de esta institución (105).

\subsection{Funciones y actividades de la Orden de Santiago}

El estudio de las funciones desarrolladas por Santiago entre 1350 y 1500 es fundamental de cara a obtener una imagen completa de su evolución histórica y de las razones que 
propiciaron su transformación a lo largo de la Edad Media. Por todo ello resulta muy llamativa, por ejemplo, la poca frecuencia con que se ha abordado la actividad militar de las órdenes (a pesar de ser la principal), así como que no se haya compuesto todavía una obra de carácter monográfico sobre ella. A eso hay que añadir que, actualmente, las pocas investigaciones que se han llevado a cabo en relación con la materia han consistido en una mera descripción del papel que los freires jugaron en los distintos conflictos armados que tuvieron por escenario la Península Ibérica ${ }^{7}$. Consecuentemente, son todavía muchos los progresos que han de realizarse dentro de la presente línea de conocimiento.

Observamos que dichas investigaciones son especialmente parcas a la hora de tratar la participación santiaguista en la guerra contra otros hermanos de fe. De hecho, solo el profesor Carlos de Ayala se ha internado en estas cuestiones para el periodo cronológico que nos atañe, y más concretamente, durante las famosas guerras civiles castellanas (29). Algo más abundante es, sin embargo, el número de publicaciones de que disponemos para conocer el grado de efectividad que estos instrumentos de la Cristiandad y de la propia monarquía alcanzaron en las zonas fronterizas con al-Ándalus. De un lado, están aquellas que nos ofrecen una visión completa acerca de la presencia que tuvieron en estos cambiantes espacios a lo largo de los siglos XIII y XIV, como las de P. Josserand $(\mathbf{5 8}, \mathbf{6 1})$ y la del ya mencionado Carlos de Ayala (32); mientras que, de otro, están las que inciden en sectores específicos de las extremaduras, como sucede con la de López Fernández (70) Suárez Fernández (123) y Rodríguez Picavea (116).

Tampoco la dimensión espiritual y religiosa de los freires escapa al problema anterior; y es que esta no ha sido una de las áreas de atención preferente para los historiadores hasta hace aproximadamente una década. La devoción constituye, en definitiva, uno de los grandes temas olvidados en el estudio de las milicias hispánicas, y particularmente en lo que al Bajo Medievo se refiere. Prueba de ello es el hecho de que solo hayamos localizado cuatro trabajos de estas características: el de Ballesteros Linares (34), el de Echániz Sans (48), el de Arcaz Pozo (25), el de Rodríguez Blanco (107) y el de Madrid Medina (76).

En último término, creemos necesario citar la original aportación que Peinado Santaella hizo en la década de 1980 en torno a otra de las funciones propias de este tipo de instituciones: la asistencial (94). A través de ella puede apreciarse el papel ejercido por los hospitales en los señoríos andaluces de Santiago en el paso del Medievo a la Edad Moderna. Desgraciadamente, se trata de la única que existe en la actualidad para el periodo cronológico en el que nos movemos ${ }^{8}$.

\footnotetext{
7 Carlos de Ayala Martínez: "Balance y actualidad de la historiografía de Órdenes Militares en los reinos medievales de León y Castilla (2004-2014)", Cuadernos de Cehimo, 41 (2014), p. 112.

8 Para profundizar en estas cuestiones véanse los artículos: Ángela MadRID Medina: "La presencia de hospitales santiaguistas en el Camino de Santiago", El museo de Pontevedra, 51 (1997), pp. 513-526 y Ángela MAdrid Medina: "Los comienzos de la hospitalidad santiaguista: el Hospital de Ávila", Espacio, tiempo y forma. Serie III. Historia medieval, 17 (2004), pp. 371-380. Aunque no se ajustan a nuestros límites cronológicos, son muy valiosos de cara al estudio de la hospitalidad santiaguista.
} 


\subsection{Santiago y su relación con los restantes poderes políticos y eclesiásticos}

La bibliografía de que disponemos para conocer los lazos existentes entre las órdenes militares hispánicas y las restantes autoridades políticas y eclesiásticas del reino es cuantiosa pero claramente desigual. Esto es debido a que los especialistas han concedido un mayor protagonismo al estudio de su vinculación con los poderes laicos, mientras que los eclesiásticos han sido relegados a un segundo plano. Por consiguiente, y como acabamos de introducir, la naturaleza de sus contactos con la monarquía se ha venido investigando desde hace ya muchos años; de modo que las obras que actualmente giran alrededor de estos aspectos son relativamente numerosas (aunque ninguna de ellas profundiza en el caso santiaguista de manera particular). Y es que, la temática presenta un gran atractivo para los medievalistas; dado que fue a mediados de la decimocuarta centuria cuando culminó ese proceso de afirmación del poder real y de intervencionismo en el desarrollo de las milicias (124).

Quien mejor ha detallado dicho proceso ha sido el profesor Carlos de Ayala, que se ha adentrado en las reformas que los reyes acometieron sobre estos organismos peninsulares para ejercer un mayor y más efectivo control de sus estructuras de poder y de sus realidades económicas $(\mathbf{2 7}, \mathbf{3 1})$. Pero también Díaz Martín y Mitre Fernández han progresado en esta línea y lo han hecho mediante el análisis de las intrusivas políticas que Pedro I y la dinastía Trastámara aplicaron en este sentido $(\mathbf{4 6}, \mathbf{8 4})$. De otro lado, circunscritas al gobierno de los Reyes Católicos en particular estarían las publicaciones de Javierre Mur (55), Rodríguez Blanco (107) y Madrid Medina (76).

Dentro de este campo se hallan, además, las prolijas investigaciones que han visto la luz acerca de la proximidad entre Santiago y los contextos nobiliarios a fines del Medievo. En esta ocasión, la tendencia historiográfica que observábamos anteriormente vuelve a repetirse, aunque de manera algo más tardía; ya que no ha sido hasta hace relativamente poco tiempo cuando el tema ha empezado a recibir una verdadera atención por parte de los expertos.

Entre todos esos estudios que han aparecido a lo largo de los años sobre esta otra faceta de las milicias, solo dos ofrecen una visión conjunta de la materia: el de Arcaz Pozo, que analiza sus nexos con la nobleza gallega (22) y el de González Sánchez, que destaca el control que ciertos linajes e individuos (procedentes de la media y baja nobleza la mayor parte de las veces) ejercieron sobre sus encomiendas (54). Los restantes, por el contrario, tienen un carácter algo más concreto. Así ocurre, por ejemplo, con el de Rodríguez Llopis, que consiste en un análisis de los vínculos de parentesco que unían a los freires santiaguistas con este grupo social en el siglo XV (114); o con el de Calderón Ortega, que da cabida a las pugnas que tuvieron lugar entre varios miembros de la aristocracia que intentaban hacerse con el control de la rentable encomienda de Azuaga entre 1465 y 1478 (40).

Si bien es cierto que los avances que la historiografía ha logrado en los casos anteriores son sustanciales, la situación cambia cuando fijamos nuestra atención en el carácter 
que tuvieron las relaciones entre estas instituciones religioso-guerreras y los concejos (tanto de realengo como de su propia jurisdicción). Y es que, todavía hoy siguen siendo minoritarias las obras de conjunto sobre la materia. A pesar de ello, la mayor parte de las investigaciones que los especialistas han puesto en marcha dentro de esta línea coinciden en que los contactos entre los freires y los poderes municipales no siempre fueron fáciles, especialmente en lo que a los concejos de origen real se refiere. De hecho, disponemos de varios trabajos que nos ofrecen información muy valiosa sobre los contactos que Santiago mantuvo con los núcleos poblacionales asentados en sus territorios, como el de Rodríguez Blanco (108), Arcaz Pozo (24) y Yelo Templado (128). Igualmente sucede con la convivencia entre esta y las villas de origen real (85).

Finalmente, solo nos resta reseñar dentro de este cuarto apartado el escaso protagonismo que se ha venido concediendo tradicionalmente a las posturas mantenidas por las autoridades eclesiásticas ante las milicias asentadas en la Península Ibérica, en general y los hermanos santiaguistas, en particular. Las excepciones a esta constante las constituyen las aportaciones de Díaz Ibáñez (45), Torija Fernández (125) y Raquel Torres (126).

\subsection{Fuentes y documentos editados}

Antes de finalizar nuestro recorrido por la amplia producción historiográfica que se ha generado en torno al desarrollo histórico de Santiago en la Castilla bajomedieval, consideramos oportuno detenernos en un proceso de gran trascendencia dentro de su estudio: la edición de fuentes documentales. Y es que dicho proceso, junto a la composición de guías y regestas, agiliza enormemente la tarea del investigador; ya que no olvidemos que los datos más relevantes sobre estas instituciones son precisamente los que se derivan del análisis de los documentos procedentes de sus antiguos archivos, conservados en su mayoría en la Sección de Órdenes Militares del Archivo Histórico Nacional de Madrid. Concretamente sobre esta misma sección se han preparado algunos índices con la intención de facilitar el acceso a sus fondos. Hablamos de la Guía de la Sección de las órdenes militares de Javierre Mur y Gutiérrez del Arroyo (19), de los Archivos y documentos medievales de las Órdenes Militares de Romero Fernández Pacheco (20) y del catálogo de Privilegios reales de la Orden de Santiago también de Gutiérrez del Arroyo (18).

En la mayoría de las ocasiones, el procedimiento adoptado por los especialistas para hacer frente a esta labor a la que nos venimos refiriendo consiste en la publicación de fuentes que atañen a una única milicia; aunque excepcionalmente dichas fuentes pueden estar ligadas a varias de ellas. Esto es lo que sucede con la edición facsimilar de la Chronica de las tres ordenes y Cavallerias de Sanctiago, Calatrava y Alcantara de Francisco de Rades y Andrada, que recoge la historia de estos organismos desde el momento mismo de su creación hasta fines del siglo XV y principios del XVI (16) y con la Historia de las órdenes militares de Santiago, Calatrava y Alcántara desde su fundación hasta el Rey don Felipe Segundo de Caro de Torres (13). 
En lo concerniente a nuestra protagonista, la publicación de fuentes no solo se mantiene activa en mayor o menor grado actualmente, sino que se remonta a la década de los setenta, cuando vieron la luz una reedición de la Estoria de la Orden de la caualleria del Señor Santiago del Espada (15) y una crónica de su último maestre, don Alonso de Cárdenas, redactada por dos de sus comendadores (17). Fue también durante estos años cuando, a falta de una reimpresión del Bullarium Equistris Ordinis S. Iacobi de Spatha de López Arguleta (1), apareció una valiosa edición facsímil del Apuntamiento Legal de Bernabé Chaves, que recogía los dominios pertenecientes a la entidad con motivo de las donaciones reales y las repetidas concesiones de términos y heredades (3). A unas y a otras se sumarían, igualmente, el estudio que Gonzalo Chacón dio a conocer en 1940 acerca de la crónica del famoso don Álvaro de Luna y sus circunstancias (14); y la colección diplomática que sobre este mismo personaje ha editado José Manuel Calderón Ortega (2).

Además de las fuentes de carácter legal que acabamos de mencionar, contamos con un elevado número de repertorios documentales, circunscritos todos ellos a distintas regiones de la geografía peninsular en las que los freires santiaguistas tenían una fuerte presencia. Así ocurre con el que Jiménez Rayado y sus colaboradores, que reúne los Libros de Visitas de la institución en la provincia de Cuenca en los siglos XV y XVI (7); el de Juan Torres Fontes con los documentos expedidos por el concejo de Cehegín entre los el XIII y XV (12); y los que Rodríguez Llopis para Moratalla y varios señoríos santiaguistas del reino de Murcia $(\mathbf{1 0}, \mathbf{1 1})$. Más específicas son, sin embargo, la publicación de Manuel Garrido sobre los castillos extremeños (6) y la de Morales Múñiz acerca de la cancillería del príncipe-rey Alfonso de Castilla (8).

En último lugar, solo nos restaría hacer mención a esos valiosos análisis informativos que se han realizado sobre determinados fondos archivísticos. Hablamos, de un lado, del que José María Fernández Catón llevó a cabo en 1981 y que ha dado como fruto una descripción de las fuentes conservadas del priorato de San Marcos (5); y, de otro, del que Justiniano Rodríguez ha elaborado en torno a las fuentes santiaguistas obrantes en el Archivo Histórico Municipal de León, en el Catedralicio Legionense, en el de la Real Colegiata-Basílica de San Isidro y en el de la Iglesia Parroquial de Nuestra Señora del Mercado (9).

\section{Consideraciones finales: vacíos informativos y nuevas líneas de estudio}

Nuestra intención durante las páginas precedentes no ha sido otra que componer un "estado de la cuestión", que integre las obras más importantes que se han redactado sobre la Orden de Santiago en la Castilla bajomedieval; ya que así hemos conseguido obtener una visión general de los progresos alcanzados hasta nuestros días y de aquellos campos que han merecido una menor atención por parte de los especialistas.

Llegados a este punto, hay que advertir que tanto la producción bibliográfica como el volumen de fuentes que han sido editadas en torno a esta entidad son abundantes, 
pero ciertamente desiguales. Son sustancialmente más numerosos los documentos de que disponemos para conocer el siglo XV, mientras que aquellos que hacen alusión a la centuria inmediatamente anterior son claramente más escasos. Por consiguiente, resultan mayores los conocimientos que la historiografía posee en torno a los freires santiaguistas en las décadas finales del periodo medieval. De igual forma ocurre con los distintos aspectos políticos, institucionales, económicos, organizativos y religiosos que los rodean.

En cualquier caso, de la lectura de las páginas que integran el presente artículo se desprende una conclusión evidente: a pesar del interés que los expertos han mostrado por estos organismos, el tema dista de estar agotado y nuestros conocimientos de ser completos; ya que aún hoy en día perviven problemas que dificultan su comprensión. De hecho, todavía continúan girando numerosos interrogantes en torno a ellos, lo que favorece la apertura de novedosas líneas de estudio y la publicación de nuevas monografías. Así lo evidencian el volumen sobre élites y órdenes aparecido en marzo de 2015 (62) y el de órdenes y construcción de la sociedad occidental que ha visto la luz hace solo unos meses (127).

Por todo ello, se van a proponer a continuación varias líneas de trabajo vinculadas a Santiago en su etapa bajomedieval, que en la actualidad no han recibido la atención necesaria o que, simplemente, permanecen en un plano secundario. Retos de futuro que, a nuestro juicio, son imprescindibles de cara a obtener un conocimiento completo sobre la materia. Estas, no obstante, pueden extrapolarse también, en mayor o menor medida, a las restantes instituciones religioso-guerreras.

La primera tarea pendiente sería la composición de obras de síntesis que recojan todas y cada una de las etapas de la evolución medieval de esta entidad, así como otras que aborden su desarrollo institucional bajo el gobierno de la dinastía Trastámara. Y es que, aunque en el transcurso de los últimos veinte años han sido varios los especialistas que se han atrevido a redactar libros de carácter general, que aglutinan a la totalidad de las milicias nacidas en suelo peninsular; aún no se han realizado los mismos esfuerzos para el caso del que ahora nos ocupamos. Por consiguiente, son realmente minoritarios (además de antiguos) los estudios de estas características que existen hoy en día.

Este mismo problema afecta también a otros dos campos. En primer lugar, a los estudios comparativos; una nueva tendencia dentro de la investigación que apenas hoy recibe atención, pero que poco a poco empieza a cobrar algo de fuerza entre los medievalistas más jóvenes y que puede aportar datos ciertamente interesantes y novedosos. Y es que la comparación (particularmente la geográfica) es esencial a la hora de reconstruir la Historia porque nos permite hallar similitudes, e incluso patrones, en la evolución de los distintos espacios y grupos humanos; así como reforzar hipótesis anteriores ${ }^{9}$.

\footnotetext{
9 Para obtener un conocimiento más profundo de la historia comparativa se recomienda consultar: WicKHAM: “Tradiciones nacionales y el problema de la comparación”, Anales de Historia Antigua, Medieval y Moderna, 40 (2008), pp. 11-23.
} 
En segundo término, se encontrarían los análisis prosopográficos, que favorecen la obtención de un conocimiento más profundo de los miembros que conformaban las milicias. Hablamos de una labor imprescindible de cara a entender los lazos que se entablaron entre los distintos sectores de la aristocracia y estas entidades; dado que la creciente intromisión nobiliaria en ellas no fue una tendencia generalizada desde el mismo momento en que surgieron. Por ende, solo a través de una lectura detallada y minuciosa de las trayectorias biográficas de los personajes que ocuparon sus más altas dignidades, es posible comprender la verdadera magnitud de este fenómeno ${ }^{10}$.

La organización del patrimonio santiaguista y el gobierno y la administración de sus posesiones en la mitad norte de la Península Ibérica es otra de las asignaturas pendientes de la historiografía. Esto es debido a que las obras que actualmente se centran en estas cuestiones son muy prolijas, pero claramente desiguales; de modo que apenas se tienen datos de la presencia de esta institución en determinadas áreas durante las centurias finales de la Edad Media. Es lo que sucede, como ya tuvimos ocasión de comprobar, con el territorio gallego y otros puntos del Cantábrico, para los cuales las investigaciones son algo parcas en este sentido a causa de la escasa documentación disponible.

También alrededor de la vida económica y el fisco en estos señoríos giran algunos interrogantes que no han podido ser resueltos por el momento. Nos referimos concretamente a la polémica que se generó allá por la década de 1970 en torno a la estructuración de las rentas feudales, como consecuencia del replanteamiento crítico que Jesús Martínez Moro hizo de las delimitaciones jurídicas establecidas por Salvador Moxó. Fue precisamente este autor quien replanteó desde una perspectiva innovadora el tema de su clasificación; llegando a la conclusión de que no existe un único sistema que encasille absolutamente todos los conceptos en virtud de los cuales los señores reclamaban sus pagos y que un excesivo formalismo jurídico puede deformar la visión de conjunto de estas rentas ${ }^{11}$. Y es que, como también han advertido Peinado Santaella y Rodríguez Llopis, las relaciones que de ellas nos ofrecen los Libros de Visita combinan de forma confusa y desordenada sus distintos tipos ${ }^{12}$.

Pero no han sido estas las únicas ramas de la investigación que no han recibido la atención necesaria por parte de la historiografía. Tampoco la dimensión interna y los aspectos sociológicos de Santiago durante los siglos XIV y XV ha sido una de las áreas de preocupación dominante en estos años; de modo que esta faceta de las órdenes sigue componiendo una línea de estudio abierta y a la espera de nuevos planteamientos. Resulta especialmente llamativo que ni siquiera el papel que la mujer ocupaba dentro de ellas, uno de los temas que mayor curiosidad ha suscitado entre los expertos de un tiempo a esta parte, se vea libre de este problema. De hecho, son

\footnotetext{
10 Carlos de Ayala Martínez: "Balance y actualidad de la historiografía...,", p. 115.

11 Jesús Martínez Moro: La renta feudal en las Castilla del siglo XV: los Stúñiga. Valladolid, 1977.

12 Rafael Peinado Santaella: "Estructura de la renta feudal en los señoríos andaluces de la Orden de Santiago a finales de la Edad Media. I Encomiendas orientales", Actas del I Coloquio de Historia de Andalucía. Andalucía Medieval, Córdoba, 1982, pp. 471-473.
} 
todavía muchos los vacíos informativos que quedan por cubrir en este sentido; puesto que incluso algunas de las teorías más aceptadas hasta hace poco son ahora puestas en duda por algunos especialistas.

Esto es lo que ocurre, sin ir más lejos, con la idea de la igualdad entre freires y freiras y las limitaciones a las que estas últimas hubieron de hacer frente dentro de las milicias. Tradicionalmente, en la Historia de la mujer había imperado la creencia de que la ausencia del colectivo femenino en determinados ámbitos se debía a su imposibilidad de acceder a ellos y a su condicionamiento por parte de la sociedad. Por consiguiente, las freiras habrían formado parte de las instituciones religioso-guerreras desde un principio y habrían creado en ellas un espacio propio de vida material y espiritual, pero no habrían podido disfrutar de todas las posibilidades que estas ofrecían, dado que les estaba vetada la participación en la guerra y el acceso a los principales órganos de gobierno. Estas premisas, hasta entonces completamente aceptadas, empezaron a ser cuestionadas en un controvertido artículo que Milagros Rivera Garretas publicó en el año 1997'13; en el cual se planteaba que no siempre la falta de mujeres en determinados lugares se debía a que no habían tenido la oportunidad de integrarse en ellos, sino que simplemente a veces no habían querido hacerlo. Es decir, que se ha tendido a interpretar erróneamente el hecho de que las freiras no guerrearan con que no podían hacerlo; aunque de las fuentes no se desgaja el más mínimo indicio que nos haga pensar que ellas deseaban realizar esta actividad.

Teniendo en cuenta esta nueva hipótesis, Rivera Garretas nos invita a reflexionar acerca de la supuesta marginación de la que fue víctima el sexo femenino en el seno de las órdenes militares; pues en ocasiones lo que puede verse como un signo de desigualdad o de inferioridad no es más que el ejercicio de la libertad personal. Se trata, en definitiva, de una visión diferente que habrá de ser tenida en cuenta en cierta medida a la hora a ahondar en los espacios que las mujeres construyeron en estas entidades en el contexto de la sociedad medieval peninsular.

Si bien es cierto que los trabajos sobre la organización interna y la caracterización sociológica santiaguista son minoritarios, la situación cambia radicalmente cuando dirigimos nuestra mirada hacia su funcionamiento institucional y a la distribución del poder; porque los especialistas suelen mostrar un interés especial por los miembros de las grandes familias nobiliarias, encargados de la gestión de sus recursos y de sus políticas. Consecuentemente, en las últimas décadas los maestres y sus soportes económico-institucionales (los maestrazgos) han disfrutado de un notable protagonismo dentro de la historiografía.

Por el contrario, y aquí radica la dificultad, el estudio de las restantes dignidades, tanto laicas como eclesiásticas, constituyen un porcentaje mínimo de la bibliografía relacionada con la materia, a causa de la escasa popularidad que viene rodeando al tema desde un

13 Milagros Rivera Garretas: "La Orden de Santiago: freiles y freilas ante el poder", Relaciones de poder en Castilla: el ejemplo de Cuenca, Joaquín Saúl García Marchante y Ángel Luis López Villaverde (eds.): Cuenca, 1997, pp. 133-145. 
principio. Por ende, las obras que han salido a la luz sobre comendadores mayores y demás cargos y oficios son infinitamente más reducidas que aquellas sobre las figuras maestrales; especialmente en lo que afecta a los priores y sacristanes encargados de las necesidades eclesiásticas de los freires.

Este mismo problema atañe igualmente al campo de las relaciones que se entablaron con los restantes poderes políticos y eclesiásticos castellanos; debido a que tradicionalmente se ha concedido una mayor atención a su vinculación con las autoridades laicas, mientras que las eclesiásticas han sido relegadas a un segundo plano. Específicamente la naturaleza de los contactos que se establecieron con la monarquía, la nobleza y los órganos concejiles en el transcurso de la Baja Edad Media, se ha venido investigando desde hace ya muchos años y no ha dejado de hacerse. Sin embargo, han sido pocos los autores que se han esforzado por descubrir las posturas adoptadas por los poderes eclesiásticos ante ellas.

Tampoco las funciones y actividades militares, religiosas y hospitalarias en las que se empleaban los freires entre los años 1350 y 1500 gozan de peso entre la bibliografía centrada en estos organismos; aunque dichas obligaciones resultan fundamentales de cara a obtener una imagen completa de su evolución histórica y de las razones que propiciaron su transformación a lo largo de la Edad Media. Por todo ello, los progresos alcanzados en este sentido son leves y las incógnitas muy numerosas.

Concretamente su dimensión religiosa y espiritual (y no digamos ya la hospitalaria) ha sido uno de los grandes temas olvidados en el estudio de las milicias hispánicas, y sobre todo en lo que al Bajo Medievo se refiere. No ha logrado despertar la curiosidad de los historiadores hasta hace aproximadamente una década, por lo que el número de publicaciones de que se disponen sobre él es muy reducido, como ya hemos tenido oportunidad de comprobar.

Por otra parte, en lo que respecta a su intervención en los diferentes conflictos armados de los siglos XIV y XV, resulta especialmente llamativa la escasa frecuencia con la que se ha abordado esta cuestión; ya que las órdenes fueron creadas principalmente para luchar contra los musulmanes andalusíes. A esto hay que añadir, además, que no se ha compuesto actualmente ninguna obra de carácter monográfico sobre la materia y que las pocas investigaciones que se han llevado a término sobre la misma han consistido en muchas ocasiones en una mera descripción del papel que los freires jugaron en los distintos enfrentamientos bélicos que tuvieron por escenario la Península Ibérica y no han profundizado en el análisis de sus acciones ${ }^{14}$. Lamentablemente, este reto de futuro resultará especialmente difícil de superar para la historiografía española, a causa de la parquedad documental y el reducido número de datos de que disponemos.

Llegados a este punto, solo nos resta hacer mención a dos últimas líneas de trabajo pendientes de atención. De un lado, la que tiene que ver tanto con la edición de fuentes documentales, como con la de índices y regestas que faciliten su conocimiento y un mejor acceso a los archivos históricos. No vamos a negar, ni mucho menos, que los

14 Carlos de Ayala Martínez: "Balance y actualidad de la historiografía...”, p. 112. 
avances que se han producido en este campo hasta el momento son loables y que esta tendencia ha gozado de un relativo protagonismo desde hace ya varias décadas dentro del estudio de las órdenes militares hispánicas. Sin embargo, no está de más recordar que dichas ediciones solo son coyunturales y que la realización de esta tarea de forma sistemática no se ha intentado todavía para Santiago. Recapitulando, contamos en la actualidad con una cantidad nada desdeñable de documentos generados por estos organismos, por lo que la necesidad de intensificar y sistematizar su proceso de publicación es toda una realidad de nuestro tiempo.

De otro lado, el análisis de las crónicas bajomedievales es igualmente obligatorio si se quiere alcanzar una imagen realmente completa de la temática. En esta ocasión, puede que sea el precario desarrollo historiográfico o simplemente la falta de interés el motivo que explica la escasa atención que los medievalistas han concedido al papel de las milicias dentro de la cronística y a la imagen que de ellas se proyectaba. Únicamente sabemos de la existencia de dos trabajos que profundicen en la materia de manera general: los que el profesor Philippe Josserand elaboró en 2002 y 2003 respectivamente ${ }^{15}$. Para concluir, solo nos gustaría advertir que, aunque nuestra intención a lo largo del presente artículo ha sido realizar una revisión, lo más exhaustiva posible, del estado en el que se hallan las investigaciones sobre Santiago a fines del Medievo, esta se encuentra lejos de ser definitiva y las conclusiones formuladas quedan abiertas a ulteriores revisiones, como ocurre siempre en los estudios históricos, y más con los de carácter recopilatorio.

\footnotetext{
15 Philippe Josserand: "Enjeux de pouvoir et traitement historiographique: les ordres militaires dans la chronique royale castillane aux XIIIe et XIVe siècles", Cahiers de linguistique et de civilisation hispaniques médiévales. 25 (2002), pp. 183-193; y Philippe Josserand: "Les ordres militaires dans la chronique castillane à l'époque de Rodrigo Jiménez de Rada", Cahiers de linguistique et de civilisation hispaniques médiévales, 26 (2003), pp. 123-132. A ambos trabajos conviene añadir el del profesor Carlos Barquero Goñi, de carácter algo más concreto: Carlos BARQUERO GoÑI: "La Orden de San Juan en Castilla según la cronística medieval (siglos XII-XIV)", Actas del Primer Simposio Histórico de la Orden de San Juan en España. (Madrid y Consuegra, 1990). 2003, pp. 57-63.
} 


\section{Relación de fuentes editadas}

Colecciones documentales y regestas:

1. AGUADO de CÓRDOVA A.F., ALEMAN ET ROSALES, A.A. y LÓPEZ AGURLETA, I.: Bullarium Equistris Ordinis S. Iacobi de Spatha. Madrid, 1719.

2. CALDERÓN ORTEGA, J.M.: Álvaro de Luna (1419-1453). Colección diplomática. Madrid, 1999.

3. CHAVES, B.: Apuntamiento legal sobre el dominio solar de la Orden de Santiago. Barcelona, 1975. (reed. facsímil).

4. ECHÁNIZ SANS, M.: El monasterio femenino de Sancti Spiritus de Salamanca. Colección diplomática (1268-1400), Salamanca, Universidad de Salamanca, 1993.

5. FERNÁNDEZ CATÓN, J.M.: "Documentación del priorato de San Marcos de León de la Orden de Santiago, en el Archivo Diocesano de León”, Anuario de Estudios Medievales, 11 (1981), pp. 435-446.

6. GARRIDO SANTIAGO, M.: Documentos de la Orden de Santiago sobre castiellos extremeños. Cáceres, 1989.

7. JIMÉNEZ RAYADO, E., RETUERCE VELASCO, M. y SEGURA GRAIÑO, C. (coord.): Libros de Visita de la Orden Militar de Santiago. Provincia de Cuenca: siglos XV-XVI. Vol. 1 y 2. Cuenca, Asociación Cultural Al-Mudayna, 2009.

8. MORALES MUÑIZ, M.D.: "Documentación acerca de la administración de la Orden de Santiago por el príncipe-rey Alfonso de Castilla (1465-1468)", Hidalguía, 211 (1988), pp. 839-868.

9. RODRÍGUEZ FERNÁNDEZ, J.: "Documentación de la Casa de San Marcos vista en cuatro Archivos leoneses", Anuario de Estudios Medievales, 11 (1981), pp. 225-361.

10. RODRÍGUEZ LLOPIS, M.: Documentación para la Historia Medieval de Moratalla. Murcia, 1988.

11. RODRÍGUEZ LLOPIS, M.: Documentos de los siglos XIV y XV. Señoríos de la Orden de Santiago, "Colección de documentos para la Historia del Reino de Murcia”, XVII, Murcia, 1991.

12. TORRES FONTES, J.: Documentos para la historia medieval de Cehegín. Murcia, 1982.

Crónicas:

13. CARO DE TORRES, F.: Historia de las órdenes militares de Santiago, Calatrava y Alcántara desde su fundación hasta el Rey don Felipe Segundo, Administrador perpetuo dellas. madrid, 1629. 
14. CHACÓN, G.: Crónica de don Álvaro de Luna. Madrid, 1940.

15. OROZCO, P. de Y PARRA, J. de la, Comendadores de la Orden de Santiago: Estoria de la Orden de la caualleria del Señor Santiago del Espada. Manuscrito del siglo $X V$, de la Real Academia de la Historia. Prólogo de Diego de Angulo. Introducción, y transcripción, notas y apéndice del Marqués de Siete Iglesias. Badajoz, 1978.

16. RADES Y ANDRADA, F. de: Chronica de las tres ordenes y Cavallerias de Sanctiago, Calatrava y Alcantara. Toledo, 1572, ed. facsimilar, Valladolid, 2009.

17. SIETE IGLESIAS, M. de: Alonso de Cárdenas, último maestre de la Orden de Santiago. Crónica inédita de dos de sus comendadores. Institución Pedro de Valencia, Diputación Provincial de Badajoz, 1976.

Guías de Archivos:

18. GUTIÉRREZ DEL ARROYO, C.: Privilegios reales de la Orden de Santiago en la Edad Media. Catálogo de la serie existente en el Archivo Histórico Nacional. Madrid, (s. a.).

19. JAVIERRE MUR, A. Y G. DEL ARROYO, C.: Guía de la Sección de las órdenes militares. Archivo Histórico Nacional. Patronato Nacional de Archivos Históricos. Madrid, s.f.

20. ROMERO FERNÁNDEZ PACHECO, J.R.: "Archivos y documentos medievales de las Órdenes Militares en el Archivo Histórico Nacional” en TORRES JIMÉNEZ, R. y RUIZ GÓMEZ, F. (coord.): Órdenes militares y construcción de la sociedad occidental. Cultura, religiosidad y desarrollo social de los espacios de frontera (siglos XII-XV). Madrid, Sílex, 2016, pp. 31-78

\section{Relación bibliográfica}

21. ÁLVAREZ PALENZUELA, A.: "Enrique, infante de Aragón, maestre de Santiago", Medievalismo, 12 (2002), pp. 37-89.

22. ARCAZ POZO, A.: "Nobleza y órdenes militares en la Galicia bajomedieval", $M e-$ dievalismo: Boletín de la Sociedad de Estudios Medievales, 5 (1995), pp. 127-150.

23. ARCAZ POZO, A.: "La tenencia de fortalezas nobiliarias en Galicia y su proyección en los dominios de las órdenes militares durante la Baja Edad Media" en BARRIO BARRIO, J.A. y CABEZUELO PLIEGO, J.V.: La fortaleza medieval: realidad y símbolo. 1998, pp. 243-256.

24. ARCAZ POZO, A.: "Reglamento local de los concejos santiaguistas en la Corona de Castilla en el XV" en IZQUIERDO BENITO, R. y RUIZ GÓMEZ, F. (eds.): Las Órdenes Militares en la Edad Media. Volumen I. Cuenca, Universidad de Castilla-La Mancha, 2000, pp. 861-878. 
25. ARCAZ POZO, A.: "La práctica religiosa a través de los Libros de Visitas en los señoríos santiaguistas de Galicia a fines de la Edad Media” en Iglesia y religiosidad en España: historia y archivos. Actas de las V Jornadas de Castilla-La Mancha sobre investigación en archivos. Guadalajara, 2001-2002, pp. 695-713.

26. AYALA MARTÍNEZ, C. de, RODRÍGUEZ-PICAVEA MATILLA, E. y otros: "Las Órdenes Militares en la Edad Media peninsular: Historiografía 1976-1992. Reinos de Castilla y León", Medievalismo: Boletín de la Sociedad Española de Estudios Medievales, 2 (1992), pp. 119-169 y 3 (1993), pp. 87-144.

27. AYALA MARTÍNEZ, C. de: "La Corona de Castilla y la incorporación de los maestrazgos", Militarium Ordinum Analecta, 1 (1997), pp. 257-290.

28. AYALA MARTÍNEZ, C. de: "Maestres y maestrazgos en la Corona de Castilla (siglos XII-XV)" en IZQUIERDO BENITO, R. y RUIZ GÓMEZ, F. (eds.): Las Órdenes Militares en la Edad Media. Volumen I. Cuenca, Universidad de CastillaLa Mancha, 2000, pp. 325-378.

29. AYALA MARTÍNEZ, C. de: "Las Órdenes Militares ante la guerra civil castellana (1366-1371)" en Poder y sociedad en la Baja Edad Media Hispánica. Estudio en homenaje al profesor Luis Vicente Díaz Martín. Universidad de Valladolid, 2002, 1, pp. 37-58.

30. AYALA MARTÍNEZ, C. de y BARQUERO GOÑI, C.: "Historiografía hispánica y Órdenes Militares en la Edad Media, 1993-2003", Medievalismo: Boletín de la Sociedad Española de Estudios Medievales, 12 (2002), pp. 101-162.

31. AYALA MARTÍNEZ, C. de: "La incorporación de los maestrazgos" en RIBOT, L., VALDEÓN, J. y MAZA, E. (eds.): Isabel la Católica y su época. Actas del Congreso Internacional 2004. Valladolid, 2007, 1, pp. 285-297.

32. AYALA MARTÍNEZ, C. de: "Presencia y protagonismo de las Órdenes Militares castellano-leonesas en la frontera (s. XIII-XIV)" en RODRÍGUEZ de la PEÑA, M.A. (dir.): Hacedores de frontera. Estudios sobre el contexto social de la Frontera en la España medieval. Madrid, 2009, pp. 161-178.

33. AYALA MARTÍNEZ, C. de: "Balance y actualidad de la historiografía de Órdenes Militares en los reinos medievales de León y Castilla (2004-2014)", Cuadernos de Cehimo, 41 (2014), pp. 105-141.

34. BALLESTEROS LINARES, M.: "La Orden de Santiago y la Iglesia en la frontera del Reino Nazarí de Granada" en TORO CEBALLOS, F. Y LINAGE CONDE, A. (eds.): Iglesias y fronteras. V Jornadas de Historia en la Abadía. Jaén, Diputación Provincial de Jaén, 2005, pp. 33-48.

35. BERNAL ESTÉVEZ, A.: Mérida, capital y encomienda de la Orden de Santiago (1490-1530). Badajoz, Diputación de Badajoz, 2013.

36. BUITRAGO OLIVER, J.C. y otros: "La encomienda de Campo de Criptana a finales del siglo XV: descripción de bienes y análisis de rentas" en I Congreso de Historia de Castilla-La Mancha, Junta de Comunidades de Castilla-La Mancha, VI, 1988, pp. 53-63. 
37. CABRERA, E.: "El acceso a la dignidad de maestre y las divisiones internas de las Órdenes Militares durante el siglo XV" en IZQUIERDO BENITO, R. y RUIZ GÓMEZ, F. (coord.): Las Órdenes Militares en la Edad Media. Volumen I. Cuenca, Universidad de Castilla-La Mancha, 2000, pp. 281-306.

38. CABRERA, E.: "Sobre los señoríos de las órdenes militares en el reino de Castilla" en ID: Feudalismo y señoríos al sur del Tajo (siglos XIII al XV). Córdoba, Publicaciones obra Social y Cultura Cajasur, 2007, pp. 15-35.

39. CALDERÓN ORTEGA, J.M.: "Las rentas de las posesiones toledanas de Álvaro de Luna. Condestable de Castilla y maestre de Santiago" en I Congreso de Historia de Castilla-La Mancha, Junta de Comunidades de Castilla-La Mancha, VI, 1988, pp. 81-86.

40. CALDERÓN ORTEGA, J.M.: "Pugnas nobiliarias para el control de las dignidades de las Órdenes militares en la Castilla bajomedieval: el caso de la encomienda de Azuaga (1464-1478)", Espacio, Tiempo, Forma, 4 (1989), pp. 97-135.

41. CALDERÓN ORTEGA, J.M.: Álvaro de Luna: riqueza y poder en la Corona de Castilla del siglo XV. Madrid, 1998.

42. CALZADO SOBRINO, M.P.: "El archivo general de la Orden de Santiago en Uclés. Historia de su emplazamiento y fábrica (1170-1872)", Medievalismo, 22 (2012), pp. 37-55.

43. CALZADO SOBRINO, M.P.: "San Marcos de León. Historia del fondo documental, fábrica e institución del Archivo de la Orden de Santiago en el Priorato de León (1170-1872)", Medievalismo, 23 (2013), pp. 101-115.

44. CARRASCO GARCÍA, G.: "Un modelo monárquico legislativo y jurídico para la Orden de Santiago. El maestre Lorenzo Suárez de Figueroa y los establecimientos de Uclés (1395) y Mérida (1403)", Espacio, Tiempo y Forma, Serie III, Historia Medieval, 24 (2011), pp. 13-68.

45. DÍAZ IBÁÑEZ, J.: "Las órdenes militares y la iglesia de Cuenca durante la Edad Media" en IZQUIERDO BENITO, R. y RUIZ GÓMEZ, F. (eds.): Las Órdenes Militares en la Edad Media. Volumen I. Cuenca, Universidad de Castilla-La Mancha, 2000, pp. 1049-1070.

46. DÍAZ MARTÍN, L.V.: "Los maestres de las órdenes militares en el reinado de Pedro I de Castilla", Hispania, XL (1980), pp. 285-356.

47. ECHÁNIZ SANS, M.: Las mujeres de la Orden Militar de Santiago. El monasterio de Sancti Spiritus de Salamanca (1268-1500). Barcelona, Universidad de Barcelona, 1990.

48. ECHÁNIZ SANS, M.: "Espiritualidad femenina en la Orden militar de Santiago (s. XII-XV)" en Religiosidad femenina. Expectativas y realidades, siglos VIII-XVIII. Madrid, 1991, pp. 115-138. 
49. FERREL VIDAL, M.: "Los monasterios femeninos de la Orden de Santiago durante la Edad Media" en Las Órdenes Militares en el Mediterráneo Occidental (siglos XIII-XVIII). Casa de Velázquez-Instituto de Estudios Manchegos, 1989, pp. 41-50.

50. FERREL VIDAL, M.: "Santa Eufemia de Cozuelos: un monasterio femenino de la Orden Militar de Santiago" en Estudios en memoria del profesor Salvador Moxó. Serie en la España Medieval. Madrid, Universidad Complutense de Madrid, 1982, pp. 337-348.

51. FRANCO SILVA, A.: Juan Pacheco, privado de Enrique IV de Castilla. La pasión por la riqueza y el poder. Granada, Universidad de Granada, 2011.

52. FRÍAS PONCE, I.: Don Juan Pacheco, marqués de Villena (1419-1474). Universidad de Educación a Distancia, Madrid, 1990.

53. GARCÍA LUJÁN, J.A.: La encomienda de Ocaña, de la Orden de Santiago, a finales del siglo $X V$. Ocaña, 1981.

54. GONZÁLEZ SANCHÉZ, S.: "La presencia de la media y baja nobleza en las Órdenes Militares durante la minoría de Juan II de Castilla", Revista de las Órdenes Militares, 7 (2013), pp. 57-70.

55. JAVIERRE MUR, A. "Fernando el Católico y las Órdenes Militares españolas" en Fernando el Católico. Vida y obra. V Congreso de Historia de la Corona de Aragón. Estudios, 1, Zaragoza, 1955, 285-300.

56. JOSSERAND, P.: "L'historiographie des Ordres Militaires dans les royaumes de Castille et de León. Bilan et perspectives de la recherche en histoire médiévale", Atalaya. Revue française d'études médiévales hispaniques, París, 9 (1998), pp. 5-44.

57. JOSSERAND, P.: "Les Ordres Militaires et le service curial dans le royaume de Castille (1252-1369)" en LEROY, B. (ed.): Les serviteurs de l'Etat au Moyen Âge. Actes du XXIX congrès de la SHMESP. París, 1999, pp. 75-83.

58. JOSSERAND, P.: “Un corps d'armée spécialise au service de la Reconquète. Les Ordres Militaires dans le royaume de Castille (1252-1369)" en Bulletin de la Société Archéologique et Historique de Nantes et de Loire-Atlantique. Nantes, 137 (2002), pp. 193-214.

59. JOSSERAND, P.: Église et pouvoir dans la Péninsule Ibérique. Les Ordres Militaires dans le royaume de Castille (1252-1369). Madrid, Casa de Velázquez, 2004.

60. JOSSERAND, P.: "L'ordre de Santiago face au récit de ses origines au tournant du Moyen Âge et d'époque moderne: variations sur 1'espace et le temps" en JOSSERAND, P. et OLIVIER, M. (eds.): La memoire des origines dans les ordres religieux-militaires au Moyen Âge. Die Erinnerung an die eigenen Ursprüngen in den geistlichen Ritterorden in Mittelalter. Münster, 2012, pp. 121-134.

61. JOSSERAND P. : "Frontier conflict, military cost and culture : the master of Santiago and the Islamic border in mid-fourteenth-century Spain" en SCHENK, J. y CARR, M. : The Military Orders. Volume 6.2. cultura and conflict in Western and Northen Europe. Routledge, New York, 2017, pp. 29-45. 
62. JOSSERAND, P.; OLIVEIRA, L. Y CARRAZ, D. (eds.): Élites et ordres militaires au moyen âge. Rencontre auour D'Alain Demurger. Madrid, Casa de Velázquez, 2015.

63. LADERO QUESADA, M.A.: “Algunos datos para la historia económica de las Órdenes Militares de Santiago y Calatrava en el siglo XV', Hispania, 30-116 (1971), pp. 637-662.

64. LADERO QUESADA, M.A.: "La Orden de Santiago en Andalucía. Bienes, rentas y vasallos a fines del siglo XV" en Historia, instituciones y documentos. Número 2. Sevilla, 1975, pp. 329-382.

65. LADERO QUESADA, M.A.: “Comentarios sobre los señoríos de las Órdenes Militares de Santiago y Calatrava en Castilla La Nueva y Extremadura a fines de la época medieval" en Las Órdenes Militares en el Mediterráneo Occidental (siglos XIII-XVIII). Casa de Velázquez-Instituto de Estudios Manchegos, 1989, pp. 169-180.

66. LADERO QUESADA, M.A.: "LA INVESTIGACiÓn SOBRE ÓRDENES MilitARES EN LA Edad Media hispánica durante los últimos decenios: Corona de Castilla y León” EN IZQUIERDO BENITO, R. y RUIZ GÓMEZ, F. (eds.): Las Órdenes Militares en la Edad Media. Volumen I. Cuenca, Universidad de Castilla-La Mancha, 2000, pp. 9-31.

67. LASARTE CORDERO, M: Estepa, encomienda santiaguista desde 1267 a 1559. Sevilla, 1977.

68. LOMAX, D. W.: "Las Órdenes Militares en la Península Ibérica durante la Edad Media", Repertorio de historia de las ciencias eclesiásticas en España, 6, Salamanca, 1976.

69. LÓPEZ FERNÁNDEZ, M.: "El maestre Gonzalo Mexía y su enterramiento en la iglesia de Santa María de Tudía”, Revista de Estudios Extremeños, 66 (2010), pp. 169-193.

70. LÓPEZ FERNÁNDEZ, M.: "Las órdenes religioso-militares en la frontera de Tarifa (1273-1388)", Al Qandir: Monografías y documentos sobre la historia de Tarifa, 12 (2012), pp. 54-65.

71. LÓPEZ FERNÁNDEZ, M. y OYOLA FABIÁN, A.: La Orden de Santiago y la vicaría de Santa María de Tudía (siglos XII-XIX), Badajoz, Diputación de Badajoz, 2014.

72. LÓPEZ ROJO, M.: "Algunos aspectos económicos de las encomiendas santiaguistas del Reino de Murcia (siglos XIII-XIV), Estudios de Deusto, 22 (1974), pp. 261-279.

73. MADRID MEDINA, A.: "La Orden de Santiago en el siglo XV: el campo de Montiel" en La orden concepcionista. Actas del Primer Congreso Internacional. Vol.II. León, 1990, pp. 519-522.

74. MADRID MEDINA, A.: "Establecimientos de Don Enrique de Aragón y don Alonso de Cárdenas", Revista de las Órdenes Militares, 3 (2005), pp. 163-256. 
75. MADRID MEDINA, A.: "Testamento de don Juan Pacheco, maestre de Santiago", Anales de la Real Academia Matritense de Heráldica y Genealogía, 9 (2005-2006), pp. 291-334.

76. MADRID MEDINA, A.: "La Orden de Santiago bajo los Reyes Católicos", Revista de las Órdenes Militares, 4 (2007), pp. 51-77.

77. MADRID MEDINA, A.: “¿Y qué se hizo de Don Jorge Manrique? A propósito de una discrepancia documental", Revista de las Órdenes Militares, 7 (2013), pp. 151-174.

78. MARTÍN DE NICOLÁS CABO, J.: "La Mancha santiaguista según los Libros de Visitas (1480-1511)”, Anuario de Estudios Medievales, 11 (1981), pp. 469-491.

79. MARTÍNEZ CARRILLO, M.L.: "Ensayo de investigación de historia agraria en torno a las relaciones de la Orden de Santiago con la agricultura murciana bajomedieval (1379)", Miscelánea Medieval Murciana, 6 (1980), pp. 205-236.

80. MATELLANES MERCHÁN, V.: "Historiografía medieval en la Orden de Santiago en los últimos años (1974-1989)", Hispania, L/2 (1990), pp. 965-985.

81. MATELLANES MERCHÁN, V.: "La estructura de poder en la Orden de Santiago, siglos XII-XIV”, La España Medieval, 23 (2000), pp. 293-319.

82. MELERO FERNÁNDEZ, I.: "El Hospital de Santiago de Toledo a fines del siglo XV”, Anales Toledanos, 9 (1974), pp. 3-116.

83. MELERO FERNÁNDEZ, I.: "Descripción del Hospital de Santiago de Toledo a fines del siglo XV", Anuario de Estudios Medievales, 11 (1981), pp. 459-463.

84. MITRE FERNÁNDEZ, E.: "Los maestres de las Órdenes Militares castellanas y la "revolución" Trastámara" en IZQUIERDO BENITO, R. y RUIZ GÓMEZ, F. (eds.): Las Órdenes Militares en la Edad Media. Volumen I. Cuenca, Universidad de Castilla-La Mancha, 2000, pp. 259-280.

85. MOLÉNAT, J. P.: "Les tolédans dans les ordres militaires du XIIe au XVe siècle" en FERNANDES I. C. F. (ed.): As Ordens Militares e as Ordens de Cavalaria na Constrçao do Mundo Occidental. Actas do IV Encontro sobre Ordens Militares. Lisboa-Palmela, 2005, pp. 261-277.

86. MUR I RAUDEL, A.: La encomienda de San Marcos. La Orden de Santiago en Teruel (1200-1556). Teruel, Instituto de Estudios Turolenses, 1988.

87. NOVO CAZÓN, J.L.: El priorato santiaguista de Vilar de Donas en la Edad Media (1194-1500). La Coruña, 1986.

88. PALACIOS ONTALVA, S.: "Los Libros de Visita de la Orden de Santiago: fuente para una Historia de la arquitectura militar" en Actas del Tercer Congreso de la Historia de la Construcción. Sevilla, 2000, pp. 751-760.

89. PEINADO SANTAELLA, R.G.: "La Orden de Santiago en Granada (1494-1508)", Cuadernos de Estudios Medievales, VI-VII (1978-1979), pp. 179-228. 
90. PEINADO SANTAELLA, R.G.: "La Orden de Santiago en Sevilla", Cuadernos de Estudios Medievales, 4-5 (1979), pp. 179-201.

91. PEINADO SANTAELLA, R.G.: "La encomienda santiaguista de Estepa a finales de la Edad Media (1495-1511)", Archivo Hispalense, 193-194 (1980), pp. 107-158).

92. PEINADO SANTAELLA, R.G.: La Orden de Santiago en Andalucía (1478-1515). Universidad de Granada, 1980.

93. PEINADO SANTAELLA, R.G.: "Estructura de la renta feudal en los señoríos andaluces de la Orden de Santiago a finales de la Edad Media. I Encomiendas orientales" en Actas del I Coloquio de Historia de Andalucía. Andalucía Medieval. Córdoba, 1982, pp. 471-507.

94. PEINADO SANTAELLA, R.G.: "La asistencia a los pobres en el señorío andaluz de la Orden de Santiago a fines de la Edad Media" en III Coloquio de Historia Medieval Andaluza. La sociedad mercantil andaluza: grupos no privilegiados. Jaén, 1984, pp. 383-401.

95. PEINADO SANTAELLA, R.G.: "Un señorío en la frontera del reino de Granada: la encomienda de Sócovos a finales de la Edad Media" en Congreso de la Historia de Albacete II. Edad Media. Albacete, 1984, pp. 240-262.

96. PEINADO SANTAELLA, R.G.: "Bienes urbanos de la Orden de Santiago en Andalucía: la encomienda de las Casas de Córdoba (siglos XIII-XVI)", En la España Medieval, 10 (1987), pp. 153-174.

97. PEINADO SANTAELLA, R.G.: "La renta señorial en las Órdenes Militares de la Corona de Castilla durante la Baja Edad Media", Historia, Instituciones, Documentos, 18 (1991), pp. 403-424.

98. PÉREZ FERNÁNDEZ-FIGARES, J.: “Arancel de los portazgos de la Orden de Santiago a fines del siglo XV”, Cuadernos de Estudios Medievales, 1 (1973), pp. 83-92.

99. PORRAS ARBOLEDAS, P.A.: "La hacienda de las órdenes militares en la Baja Edad Media castellana", Estudio en homenaje a don Claudio Sánchez Albornoz en sus noventa años. Anexos de C.H.E., 4 (1986), pp. 535-555.

100. PORRAS ARBOLEDAS, P.A.: Los señoríos de la Orden de Santiago en su provincia de Castilla durante el siglo XV. Madrid, 1982. / PORRAS ARBOLEDAS, P.A.: La Orden de Santiago en el siglo XV. La Provincia de Castilla. Madrid, 1997.

101. PORRAS ARBOLEDAS, P.A.: "La configuración de La Mancha como circunscripción santiaguista en los siglos XIV-XVI y la patria de Don Quijote" en IZQUIERDO BENITO, R. y RUIZ GÓMEZ, F. (eds.): Actas del Congreso, Tierra del Quijote. Tierra de Órdenes Militares. Junta de Comunidades de Castilla-La Mancha y Fundación Quijote, IV Centenario, Ciudad Real, 2007, pp. 299-312.

102. PRETEL MARÍN, A.: "Enrique de Aragón, Maestre de Santiago y Duque de Villena", Revista de las Órdenes Militares, 7 (2013), pp. 137-150. 
103. PRETEL MARÍN, A. y RODRÍGUEZ LLOPIS, M.: "Villanueva de la Fuente: un concejo rural en tierra de Alcaraz y una encomienda atípica de la Orden de Santiago (1213-1525)" en Anales del Centro de la Universidad Nacional de la Educación a Distancia de Albacete, 1981, pp. 95-142.

104. RIVERA GARRETAS, M.: "Dos presupuestos de reparación de la muralla de Uclés en la Edad Media", Anuario de Estudios Medievales, 11 (1981), pp. 465-467.

105. RIVERA GARRETAS, M.: "La Orden de Santiago: freiles y freilas ante el poder" en GARCÍA MARCHANTE, J. S. y LÓPEZ VILLAVERDE, A. L. (eds.): Relaciones de poder en Castilla: el ejemplo de Cuenca. Cuenca, 1997, pp. 133-145.

106. RODRÍGUEZ BLANCO, D.: La Orden de Santiago en Extremadura en la Baja Edad Media (siglos XIV-XV). Badajoz, 1985.

107. RODRÍGUEZ BLANCO, D.: "La reforma de la Orden de Santiago", La España Medieval. V Estudios en memoria del profesor Sánchez Albornoz, 2 (1986), pp. 929-960.

108. RODRÍGUEZ BLANCO, D.: "Los concejos de las órdenes militares en la Baja Edad Media. Organización y relaciones de poder", Historia, Instituciones, Documentos, 18 (1991), pp. 425-443.

109. RODRÍGUEZ BLANCO, D.: "Enrique de Aragón (1400-1445), maestre de Santiago y el capítulo general de Uclés de 1440" en IZQUIERDO BENITO, R. y RUIZ GÓMEZ, F. (eds.): Actas del Congreso, Tierra del Quijote. Tierra de Órdenes Militares. Junta de Comunidades de Castilla-La Mancha y Fundación Quijote, IV Centenario, Ciudad Real, 2007, pp. 259-277.

110. RODRIGUEZ LLOPIS, M.: Conflictos fronterizos y dependencia señorial: la encomienda santiaguista de Yeste y Taibilla (siglos XIII-XV). Albacete, 1982.

111. RODRÍGUEZ LLOPIS, M.: Señoríos y feudalismo en el reino de Murcia. Los dominios de la Orden de Santiago entre 1440 y 1515. Murcia, 1986.

112. RODRIGUEZ LLOPIS, M.: "Propiedades y censos de la Orden de Santiago en las ciudades de Murcia y Lorca (siglo XV)", Anuario de Estudios Medievales, 17 (1987), pp. 469-484.

113. RODRIGUEZ LLOPIS, M.: "Protesta popular y conflictos de clase: los levantamientos campesinos de Yeste (Albacete) en el reinado de Isabel I" en I Congreso de Historia de Castilla-La Mancha, Junta de Comunidades de Castilla-La Mancha, 1988, pp. 141-146.

114. RODRÍGUEZ LLOPIS, M.: "Poder y parentesco en la nobleza santiaguista del siglo XV”, Noticiario de la Historia Agraria, 12 (1996), pp. 57-90.

115. RODRÍGUEZ MOLINA, J.: "Las órdenes militares de Calatrava y Santiago en el Alto Guadalquivir (siglos XIII-XV)", Cuaderno de Estudio Medievales, 2-3 (1975).

116. RODRÍGUEZ-PICAVEA MATILLA, E.: "The Military Orders and the war of Granada (1350-1492)”, Mediterranean Studies, 19 (2010), pp. 21-41. 
117. RODRÍGUEZ-PICAVEA MATILLA, E.: "The Military Orders in Medieval Iberia. Image, propaganda and legitimacy", Mirator, 13 (2012), pp. 1-35.

118. RUIZ GÓMEZ, F.: Los orígenes de las órdenes militares y la repoblación de los territorios de La Mancha (1150-1250). Consejo Superior de Investigaciones Científicas, Madrid, 2003.

119. SÁNCHEZ GIL, V.: "La encomienda de la Orden Militar de Santiago del valle de Ricote (Murcia). Fundación de parroquias, 1508”, Hispania Sacra, vol. 35, 71 (1983), pp. 221-250.

120. SÁNCHEZ QUIÑONES, J.: "La pesca en los territories castellanos de las Órdenes Militares de Santiago y de Calatrava (1450-1550): Organización del espacio y técnicas pesqueras" en TORRES JIMÉNEZ, R. y RUIZ GÓMEZ, F. (coord.): Órdenes militares y construcción de la sociedad occidental. Cultura, religiosidad y desarrollo social de los espacios de frontera (siglos XII-XV). Madrid, Sílex, 2016, pp. 539-564.

121. SEGURA GRAÍÑO, C.: "La Orden de Santiago en la provincia de Madrid en la Baja Edad Media: las encomiendas de la ribera del Tajo", Anales del Instituto de Estudios Madrileños, XIX (1982), pp. 1-13.

122. SEGURA GRAÍÑO, C. y TORREBLANCA, A.: "Las órdenes militares en el reino de Córdoba en la Baja Edad Media" en Andalucía entre Oriente y Occidente (1236-1492). Actas del V Coloquio Internacional de Historia Medieval de Andalucía. Córdoba, 1988, pp. 123-134.

123. SUÁREZ FERNÁNDEZ, L.: "Las Órdenes Militares y la guerra de Granada". Sevilla, Fundación Sevillana de Electricidad, 1992, pp. 4-30.

124. TOOMASPOEG, K.: "Les ordres militaires au service des pouvoirs monarchiques occidentaux" en JOSSERAND, P.H.; OLIVEIRA, L. Y CARRAZ, D. (eds.): Élites et ordres militaires au moyen âge. Rencontre auour D'Alain Demurger. Madrid, Casa de Velázquez, 2015, pp. 321-332.

125. TORIJA RODRÍGUEZ, E.: "Las Órdenes Militares y el arzobispado de Toledo en la Baja Edad Media. Estructuración de la geografía diocesana en las zonas de frontera controladas por las Órdenes Militares y en el adelantamiento de Cazorla" en TORRES JIMÉNEZ, R. y RUIZ GÓMEZ, F. (coord.): Órdenes militares y construcción de la sociedad occidental. Cultura, religiosidad y desarrollo social de los espacios de frontera (siglos XII-XV). Madrid, Sílex, 2016, pp. 607-642.

126. TORRES JIMÉNEZ, R.: "Clérigos parroquiales en tierra de Órdenes Militares al final del siglo XV" en TORRES JIMÉNEZ, R. y RUIZ GÓMEZ, F. (coord.): Órdenes militares y construcción de la sociedad occidental. Cultura, religiosidad y desarrollo social de los espacios de frontera (siglos XII-XV). Madrid, Sílex, 2016, pp. 565-606. 
127. TORRES JIMÉNEZ, R. Y RUIZ GÓMEZ, F. (coord.): Órdenes militares y construcción de la sociedad occidental. Cultura, religiosidad y desarrollo social de los espacios de frontera (siglos XII-XV). Madrid, Sílex, 2016.

128. YELO TEMPLADO, A.: "Los vasallos mudéjares de la Orden de Santiago en el Reino de Murcia (siglos XIV-XV)", Anuario de Estudios Medievales, 11 (1981), pp. $445-458$.

Fecha de recepción: 18 de abril de 2017

Fecha de aceptación: 12 de mayo de 2017 